Check for updates

Cite this: RSC Adv., 2019, 9, 25932

Received 4th June 2019

Accepted 30th July 2019

DOI: 10.1039/c9ra04219a

rsc.li/rsc-advances

\section{Fabrication of $\mathrm{NiFe}_{2} \mathrm{O}_{4}$ acarbon fiber coated with phytic acid-doped polyaniline composite and its application as an electromagnetic wave absorber}

\begin{abstract}
Ailing Feng, ${ }^{a}$ Mingliang Ma, ${ }^{b}$ Zirui Jia, ${ }^{* c}$ Meng Zhang (D) d and Guanglei Wu (DD *ce
In this work, a novel CF@NiFe ${ }_{2} \mathrm{O}_{4}$ composite coated with phytic acid-doped polyaniline $\left(\mathrm{CF} \mathrm{aNiFe}_{2} \mathrm{O}_{4} \mathrm{ap}_{\text {- }}\right.$ PANI) was facilely synthesized. First, a typical solvothermal reaction was applied to obtain the $\mathrm{CF}\left(\mathrm{NiFe}_{2} \mathrm{O}_{4}\right.$ composite, and then the phytic acid-doped polyaniline was grown in situ on the surface of the $\mathrm{CF}\left(\mathrm{NiFe}_{2} \mathrm{O}_{4}\right.$ composite. The morphological structure, chemical composition, and surface functional group distribution of this hybrid were systematically evaluated. The magnetic saturation $\left(M_{s}\right)$ value of the hybrid is $29.9 \mathrm{emu}$ $\mathrm{g}^{-1}$, which represents an improvement in the magnetic loss. According to its reflection loss curve, the hybrid exhibits a superior EM wave absorption capacity, with a minimum reflection loss value and effective absorbing bandwidth of $-46 \mathrm{~dB}$ when the sample thickness is $2.9 \mathrm{~mm}$, and an effective absorption bandwidth of $5 \mathrm{GHz}$ when the sample thickness is $1.5 \mathrm{~mm}$. The excellent performance of this hybrid can mainly be attributed to its ideal matching of magnetic loss and dielectric loss, interfacial polarizations, eddy current loss and interface relaxation. This new material has the potential to be a superior electromagnetic wave absorber or applied as a functional filler to modify resin matrices.
\end{abstract}

\section{Introduction}

With the rapid development of science and technology in the contemporary society, the popularization and application of communication, broadcasting, electromagnetic medicine and computer technology has made electromagnetic (EM) waves pervasive in our daily lives. ${ }^{1-6}$ Therefore, the nuisance to humans caused by EM waves and the interference from related equipment are receiving increasing attention from countries around the world. ${ }^{7-10}$ Meanwhile, in order to achieve EM wave protection, research on EM wave-absorbing materials has rapidly developed. In the light of the dielectric loss and magnetic loss mechanisms of microwaves, an ideal electromagnetic wave absorber should both possess select dielectric properties and magnetic properties. Thus, the combination of

${ }^{a}$ Institute of Physics \& Optoelectronics Technology, Baoji University of Arts and Sciences, Baoji 721016, P. R. China

${ }^{b}$ Research Institute of Functional Materials, School of Civil Engineering, Qingdao University of Technology, Qingdao 266033, P. R. China

'Institute of Materials for Energy and Environment, State Key Laboratory of Bio-fibers and Eco-textiles, College of Materials Science and Engineering, Qingdao University, Qingdao 266071, P. R. China. E-mail: jiazirui@mail.nwpu.edu.cn; wuguanglei@ mail.xjtu.edu.cn; wuguanglei@qdu.edu.cn; Fax: +86 532 85951496; Tel: +86 532 85951496

${ }^{d}$ College of Electromechanical Engineering, Key Laboratory of Polymer Material Advanced Manufacturing's Technology of Shandong Province, Qingdao University of Science and Technology, Qingdao, 266061, China

${ }^{e}$ Key Laboratory of Engineering Dielectrics and Its Application, Ministry of Education, Harbin University of Science and Technology, Harbin 150080, PR China dielectric materials (such as carbon-based materials, conductive polymers, and transition metal oxides) and magnetic materials (metallic iron, cobalt, nickel and their compounds) through chemical reactions has been a classic research method to obtain predominant EM wave-absorbing composites. ${ }^{11-15}$

Due to its special conjugated molecular chain structure, polyaniline (PANI) possesses excellent electrical conductivity, a unique doping mechanism, ideal stability, high design capacity and many other advantages; therefore, PANI has been widely utilized in EM wave-absorbing and anti-electromagnetic shielding materials. ${ }^{16-19}$ PANI-based EM absorption composite materials frequently show high absorption efficiency and wide absorption bandwidths. Previous research results have shown that PANI can enhance the absorptive capacity of EM wave absorption composites through dielectric loss and eddy current loss among some other ways. ${ }^{20-24}$ Besides, its structure has an important influence on its EM wave-absorbing performance; special structural features such as its rod shape and spherical shape have received extensive attention. ${ }^{25-29}$

As a typical magnetic material, $\mathrm{NiFe}_{2} \mathrm{O}_{4}$ has been widely applied in the synthesis of efficient EM wave-absorbing composites. $\mathrm{Chen}^{30}$ and his co-workers developed a novel urchin-like PANI@carbon@ $\mathrm{NiFe}_{2} \mathrm{O}_{4}$ hybrid, which shows excellent EM wave-absorbing performance with a minimum reflection loss value of $-37 \mathrm{~dB}$. Another ideal $\mathrm{EM}$ wave absorber, a $\mathrm{NiFe}_{2} \mathrm{O}_{4} @ \mathrm{MnO}_{2} @$ @graphene composite synthesized by Wang et al., exhibits a minimum reflection loss value of $-47.4 \mathrm{~dB}$ with a sample thickness of $3.0 \mathrm{~mm} \cdot{ }^{31}$ Furthermore, the PANI@NiFe ${ }_{2} \mathrm{O}_{4} @$ graphite nanosheet, ${ }^{32} \quad \mathrm{NiFe}_{2} \mathrm{O}_{4}$-RGO- 


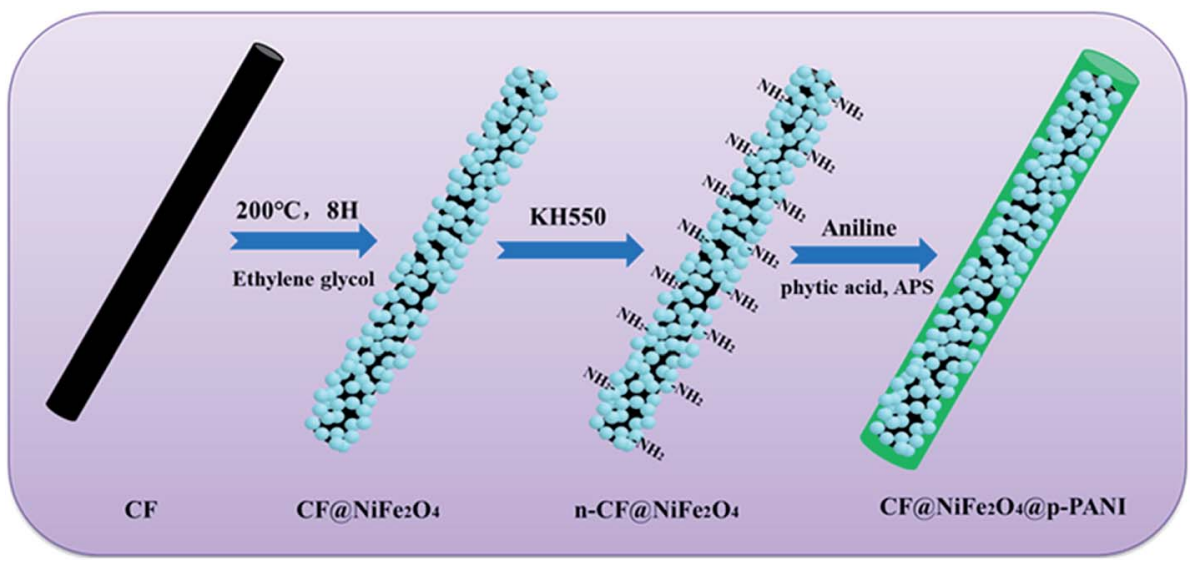

Fig. 1 Preparation process of $\mathrm{CF}\left(\mathrm{NiFe}_{2} \mathrm{O}_{4}\right.$ ap-PANI hybrid.

elastomer ${ }^{33}$ and PANI/graphene/ $\mathrm{NiFe}_{2} \mathrm{O}_{4}$ (ref. 34 ) also exhibited superior EM wave absorption properties.

In this study, a novel $\mathrm{CF} @ \mathrm{NiFe}_{2} \mathrm{O}_{4}$ composite coated with phytic acid-doped polyaniline ( $\mathrm{CF} @ \mathrm{NiFe}_{2} \mathrm{O}_{4} @ p$-PANI) was facilely prepared. First, a typical solvothermal reaction was adopted to prepare the $\mathrm{CF} @ \mathrm{NiFe}_{2} \mathrm{O}_{4}$ composite. Then, the assynthesized $\mathrm{CF} @ \mathrm{NiFe}_{2} \mathrm{O}_{4}$ composite was further coated by pPANI via in situ polymerization to obtain the $\mathrm{CF} @ \mathrm{NiFe}_{2} \mathrm{O}_{4} @$ @PANI hybrid. The morphological structure, chemical composition, magnetic properties and EM wave-absorbing features of the sample were systematically evaluated. The results prove that the hybrid possesses an excellent EM wave-absorbing capacity.

\section{Experimental}

\subsection{Materials}

The carbon fiber used in this experiment is Т300B and was supplied by Japan TORAY industries. Other reagents including ferric chloride $\left(\mathrm{FeCl}_{3} \cdot 6 \mathrm{H}_{2} \mathrm{O}\right)$, nickel chloride $\left(\mathrm{NiCl}_{2} \cdot 6 \mathrm{H}_{2} \mathrm{O}\right)$, ammonium acetate $\left(\mathrm{NH}_{4} \mathrm{Ac}\right)$, glycol, phytic acid, ammonium persulfate (APS) and aniline were purchased from Aladdin Industrial Corporation and used without further purification.

\subsection{Synthesis of $\mathrm{CF} @ \mathrm{NiFe}_{2} \mathrm{O}_{4}$ composite}

The $\mathrm{CF} @ \mathrm{NiFe}_{2} \mathrm{O}_{4}$ composite was facilely synthesized via a typical solvothermal reaction. ${ }^{24} 200 \mathrm{mg} \mathrm{CF}, 10 \mathrm{mmol} \mathrm{FeCl}_{3}$ $\cdot 6 \mathrm{H}_{2} \mathrm{O}, 5 \mathrm{mmol} \mathrm{NiCl} \mathrm{m}_{2} \cdot 4 \mathrm{H}_{2} \mathrm{O}$ and $80 \mathrm{mmol}$ ammonium acetate $\left(\mathrm{NH}_{4} \mathrm{COOH}\right)$ were homogeneously dispersed in $80 \mathrm{~mL}$ ethylene glycol phase by ultrasonication for $5 \mathrm{~min}$ and stirring for $25 \mathrm{~min}$. Then, the liquid mixture was transferred into a $100 \mathrm{~mL}$ hydrothermal reactor and kept at $200{ }^{\circ} \mathrm{C}$ for $720 \mathrm{~min}$. After naturally cooling to room temperature, the $\mathrm{CF} @ \mathrm{NiFe}_{2} \mathrm{O}_{4}$ composite was collected by $10000 \mathrm{rpm}$ centrifugation and washed with deionized water and ethanol several times.

\subsection{Preparation of $\mathrm{CF} @ \mathrm{NiFe}_{2} \mathrm{O}_{4}$ @p-PANI hybrid}

The CF@NiFe ${ }_{2} \mathrm{O}_{4} @$ @-PANI hybrid was synthesized via the in situ polymerization of aniline monomer in a liquid phase system. Before the reaction, the $\mathrm{CF} @ \mathrm{NiFe}_{2} \mathrm{O}_{4}$ composite was soaked in a mixed solution of absolute ethanol, deionized water and KH550 (wt $\%=5: 4: 1$ ) for $4 \mathrm{~h}$ to obtain the surface-aminated $\mathrm{CF} @ \mathrm{NiFe}_{2} \mathrm{O}_{4} \quad$ (n-CF@NiFe $\mathrm{O}_{4}$ ). $200 \mathrm{mg}$ as-prepared n$\mathrm{CF} @ \mathrm{NiFe}_{2} \mathrm{O}_{4}$ composite, $5 \mathrm{~mL}$ phytic acid and $100 \mu \mathrm{m}$ aniline were uniformly dispersed in $40 \mathrm{~mL}$ deionized water by $30 \mathrm{~min}$ high-speed stirring. Then, $20 \mathrm{~mL}$ ammonium persulfate

$$
\mathrm{H}_{2} \mathrm{~N}\left(\mathrm{CH}_{2}\right)_{3} \mathrm{Si}\left(\mathrm{OC}_{2} \mathrm{H}_{5}\right)_{3} \stackrel{+\mathrm{H}_{2} \mathrm{O}}{\longrightarrow} \mathrm{H}_{2} \mathrm{~N}\left(\mathrm{CH}_{2}\right)_{3} \mathrm{Si}(\mathrm{OH})_{3} \longrightarrow
$$

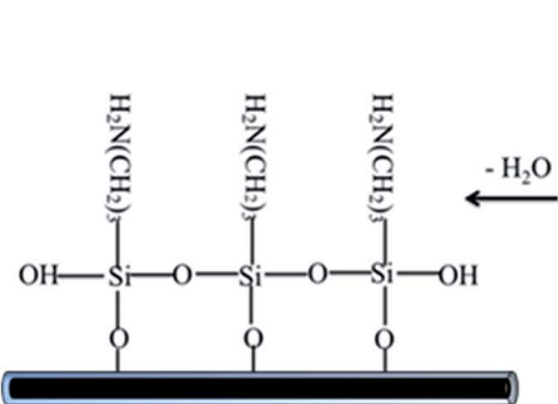

Surface of CF@ $\mathrm{NiFe}_{2} \mathrm{O}_{4}$

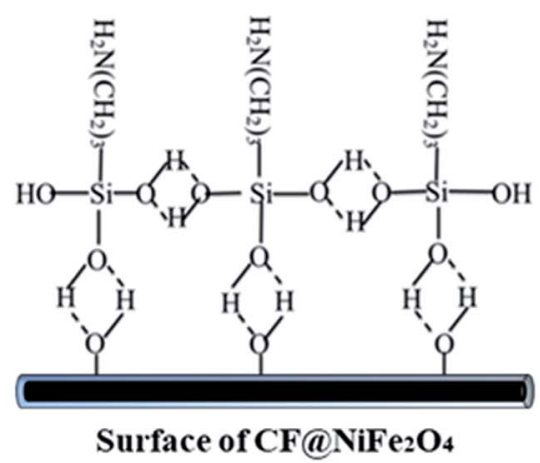

Fig. 2 Reaction mechanism illustration of $\mathrm{KH} 550$ on the surface of $\mathrm{CF}\left(\mathrm{NiFe} \mathrm{O}_{4}\right.$ composite. 
solution (APS) was slowly dripped into the mixed turbid liquid. After stirring for about 6 hours, the $\mathrm{CF} @ \mathrm{NiFe}_{2} \mathrm{O}_{4} @$ @p-PANI hybrid was separated from the liquid by $10000 \mathrm{rpm}$ centrifugation and washed with deionized water and ethanol several times. ${ }^{35-38}$

\subsection{Characterization}

The samples' surface structural features, morphologies and elemental composition proportions were identified using a scanning electron microscope (FESEM, Quanta 600FEG) equipped with an energy dispersive X-ray (EDS) accessory. Furthermore, X-ray powder diffraction (ESCALAB 250) was used to study the crystal forms of the carbon fiber, $\mathrm{NiFe}_{2} \mathrm{O}_{4}$, $\mathrm{CF} @ \mathrm{NiFe}_{2} \mathrm{O}_{4}$ composite and $\mathrm{CF} @ \mathrm{NiFe}_{2} \mathrm{O}_{4} @ \mathrm{p}-\mathrm{PANI}$ hybrid. The binding energy of the $\mathrm{CF} @ \mathrm{NiFe}_{2} \mathrm{O}_{4} @ \mathrm{p}-\mathrm{PANI}$ hybrid was examined by X-ray photoelectron spectroscopy (XPS, Thermal Scientific $\mathrm{K} \alpha$ ). The distribution of functional groups on the surface of the specimens was studied using Fourier infrared spectroscopy (FT-IR, WQF-310, China, with KBr pellets). The hysteresis loops of the magnetic specimens were measured via a vibrating sample magnetometer (VSM, Lake Shore7307). A coaxial method was adopted to obtain the complex permeability $\left(\varepsilon_{\mathrm{r}}\right)$ and permittivity $\left(\mu_{\mathrm{r}}\right)$ of the samples in the range of $2-18 \mathrm{GHz}$ using a vector network analyzer (HP8720ES). First, the specimens were uniformly distributed in a paraffin phase (the wt $\%$ of paraffin and sample is $7: 3$ ); then, they were pressed into a cylindrical mold $\left(\varphi_{\text {in }}=3.04 \mathrm{~mm}, \varphi_{\text {out }}=7.00 \mathrm{~mm}\right)$. Based on the obtained parameters of the sample, their EM wave absorption properties were further calculated..$^{39-41}$

\section{Results and discussions}

The preparation process of $\mathrm{CF} @ \mathrm{NiFe}_{2} \mathrm{O}_{4} @$ @p-PANI hybrid is briefly depicted in Fig. 1. First, a typical solvothermal reaction in a glycol phase was adopted to synthesize the $\mathrm{CF} @ \mathrm{NiFe}_{2} \mathrm{O}_{4}$ composite. Then, in order to polymerize the aniline monomer on the surface of the $\mathrm{CF} @ \mathrm{NiFe}_{2} \mathrm{O}_{4}$ composite, the sample was subjected to surface amination using KH550, and the resulting
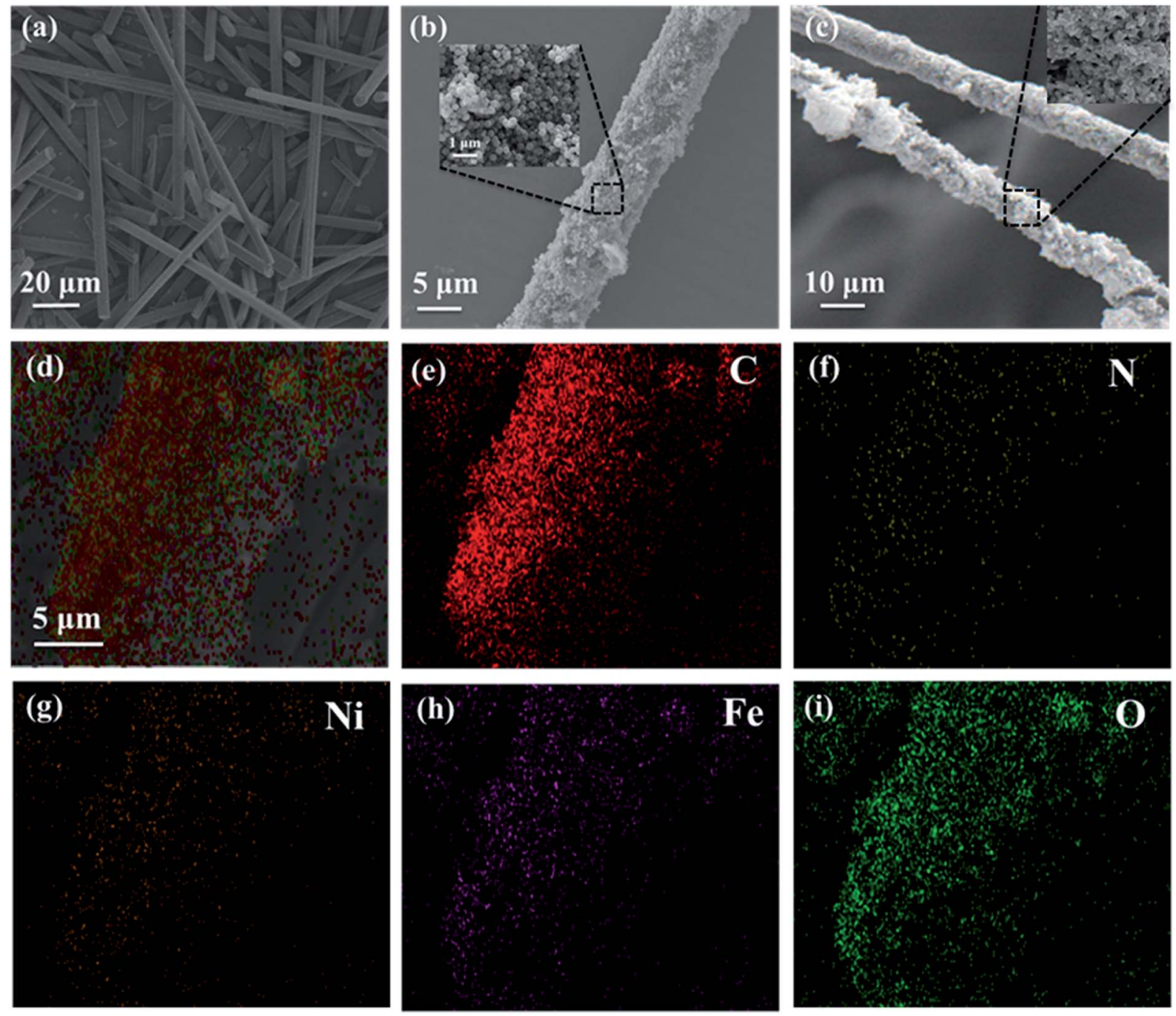

Fig. $3 \mathrm{SEM}$ images of $\mathrm{CF}(\mathrm{a}), \mathrm{NiFe}_{2} \mathrm{O}_{4}$ (b), $\mathrm{CF}\left(\mathrm{NiFe} \mathrm{O}_{4}\right.$ composite (b) and $\mathrm{CF}\left(\mathrm{NiFe} \mathrm{O}_{4}\right.$ ap-PANI hybrid (c); EDX elemental mapping images (d-i) of $\mathrm{CF} @ \mathrm{NiFe}_{2} \mathrm{O}_{4} \mathrm{ap}-\mathrm{PANI}$ hybrid. 
(a)

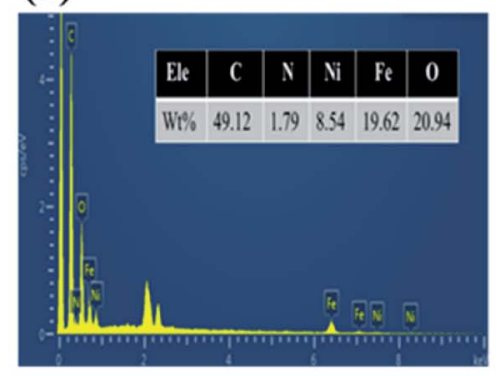

(d)

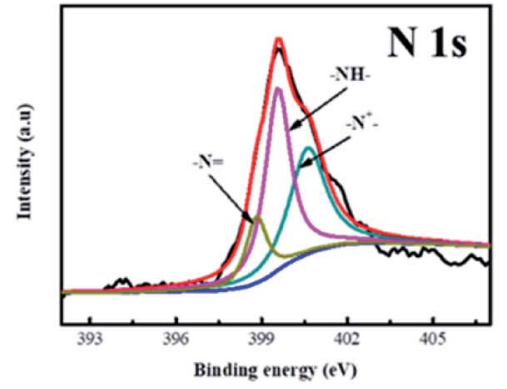

(b)

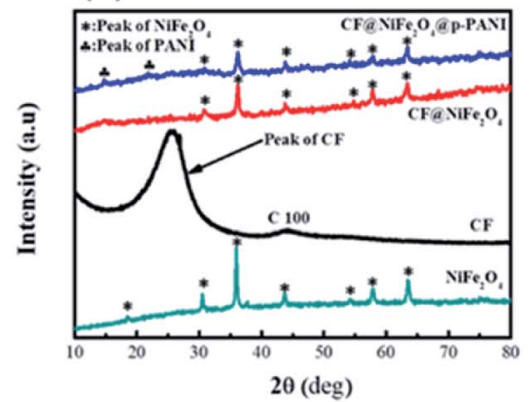

(e)

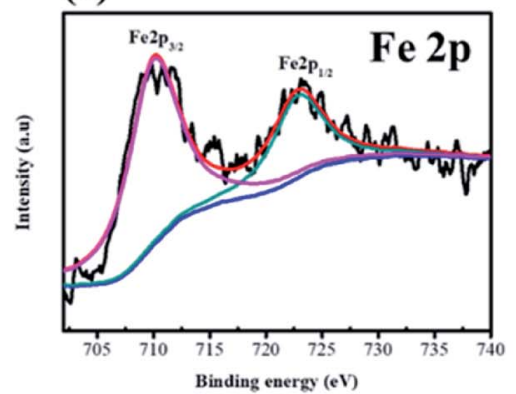

(c)

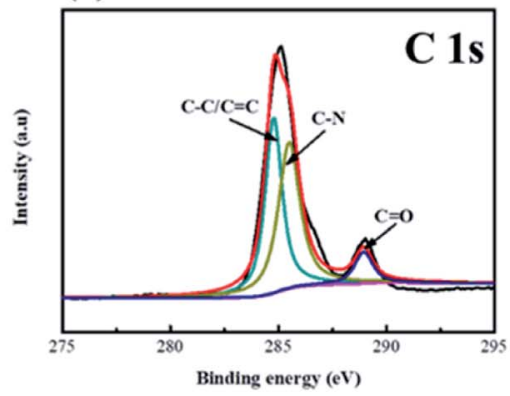

(f)

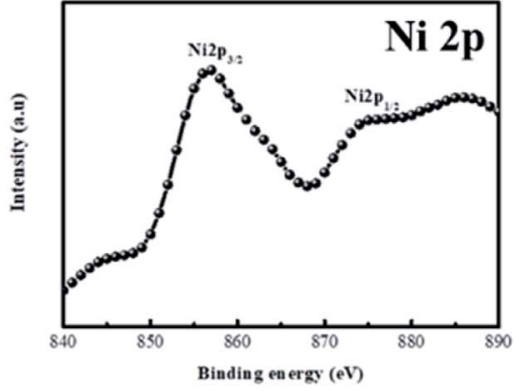

Fig. 4 EDS and XPS spectra for $\mathrm{CF}\left(\mathrm{NNiFe}_{2} \mathrm{O}_{4}\right.$ ap-PANI hybrid (a and $\left.c-f\right)$, XRD patterns of samples (b).

chemical reaction is shown in Fig. 2. Owing to the silane coupling agent's complexation with $\mathrm{H}_{2} \mathrm{O}$ molecules, after the hydration and dehydration reactions, the amino groups that had attached to the other end of the KH550 were adsorbed onto the surface of the $\mathrm{CF} @ \mathrm{NiFe}_{2} \mathrm{O}_{4}$ composite. Finally, aniline monomers were grown in situ alongside the amino groups on the surface of the $\mathrm{CF} @ \mathrm{NiFe}_{2} \mathrm{O}_{4}$ composite in a mixed system of phytic acid and water, and the $\mathrm{CF} @ \mathrm{NiFe}_{2} \mathrm{O}_{4} @$ @-PANI hybrid was obtained. ${ }^{42-44}$

Fig. 3 shows the SEM images of $\mathrm{CF}$ (a), $\mathrm{NiFe}_{2} \mathrm{O}_{4}$ (b), the $\mathrm{CF} @ \mathrm{NiFe}_{2} \mathrm{O}_{4}$ composite (b) and the $\mathrm{CF} @ \mathrm{NiFe}_{2} \mathrm{O}_{4} @$ @p-PANI hybrid (c); the corresponding EDX elemental mapping images of the hybrid are also exhibited (Fig. 3d-i). It can be observed from the images that the pre-reaction carbon fiber has a smooth surface, and its diameter is about 6-7 $\mu \mathrm{m}$. After the solvothermal reaction, the surface of the $\mathrm{CF}$ was uniformly cladded by $\mathrm{NiFe}_{2} \mathrm{O}_{4}$ nanospheres. Fig. 3c reveals the morphology of the $\mathrm{CF} @ \mathrm{NiFe}_{2} \mathrm{O}_{4} @ \mathrm{p}-\mathrm{PANI}$ hybrid, the $\mathrm{CF} @ \mathrm{NiFe}_{2} \mathrm{O}_{4}$ composite that was further coated by PANI after the in situ polymerization. The sample's EDX elemental mapping images indicate that the hybrid includes the chemical elements $\mathrm{C}, \mathrm{N}, \mathrm{Ni}, \mathrm{Fe}$ and $\mathrm{O}$, which convincingly prove the chemical composition $\left(\mathrm{C}, \mathrm{NiFe}_{2} \mathrm{O}_{4}\right.$ and PANI) of the obtained hybrid.

Fig. 4 exhibits the EDS spectra (a), XPS spectra (c-f) of $\mathrm{CF} @ \mathrm{NiFe}_{2} \mathrm{O}_{4} @$ @p-PANI hybrid and XRD patterns of the samples. From Fig. 4a, the elemental composition ratios (wt\%) of C, N, $\mathrm{Ni}, \mathrm{Fe}$ and $\mathrm{O}$ in the hybrid are $49.12 \%, 1.79 \%, 8.54 \%, 19.62 \%$ and $20.94 \%$, respectively, and these results are consistent with its EDX elemental mapping results. Fig. $4 \mathrm{~b}$ displays the XRD patterns of $\mathrm{NiFe}_{2} \mathrm{O}_{4}, \mathrm{CF}$, the $\mathrm{CF} @ \mathrm{NiFe}_{2} \mathrm{O}_{4}$ composite and the $\mathrm{CF} @ \mathrm{NiFe}_{2} \mathrm{O}_{4} @ \mathrm{p}-\mathrm{PANI}$ hybrid, which can provide information about the samples' crystal structure. The broad peak between $20-40^{\circ}$ represents the weak crystallinity of the CF. After the solvothermal reaction, 6 diffraction peaks appeared at $2 \theta=$ $30.2^{\circ}, 35.7^{\circ}, 43.4^{\circ}, 54.0^{\circ}, 57.3^{\circ}$ and $62.9^{\circ}$, which signify the (220), (311), (400), (422), (511) and (440) planes of $\mathrm{NiFe}_{2} \mathrm{O}_{4}$ (JCPDS card no. 10-0325), respectively. Compared with the $\mathrm{CF} @ \mathrm{NiFe}_{2} \mathrm{O}_{4}$ composite, the additional two peaks before $30^{\circ}$ belong to PANI. The above conclusion further proves the successful synthesis of the $\mathrm{CF} @ \mathrm{NiFe}_{2} \mathrm{O}_{4} @ \mathrm{p}$-PANI hybrid. Fig. 4c-f exhibits the XPS pattern of the $\mathrm{CF} @ \mathrm{NiFe}_{2} \mathrm{O}_{4} @ p-P A N I$ hybrid. The three peaks located at $284.6 \mathrm{eV}, 285.3 \mathrm{eV}$ and

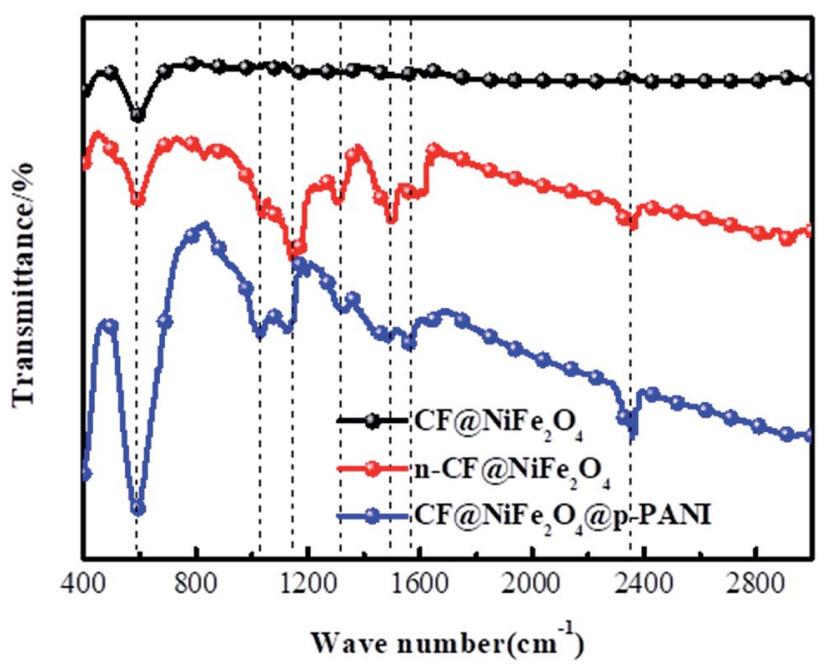

Fig. 5 FT-IR spectra of $\mathrm{CF}\left(\mathrm{NiFe}_{2} \mathrm{O}_{4}, \mathrm{n}-\mathrm{CF} \mathrm{CNiFe} \mathrm{O}_{4}\right.$ and $\mathrm{CFaNiFe} 2^{-}$ $\mathrm{O}_{4} @$ ap-PANI hybrid. 
Table 1 Adsorption peaks and the corresponding vibration modes for CFaNiFe $2 \mathrm{O}_{4}, \mathrm{n}-\mathrm{CF}\left(\mathrm{NiFe}_{2} \mathrm{O}_{4}\right.$ and CFaNiFe $2 \mathrm{O}_{4}$ ap-PANI hybrid

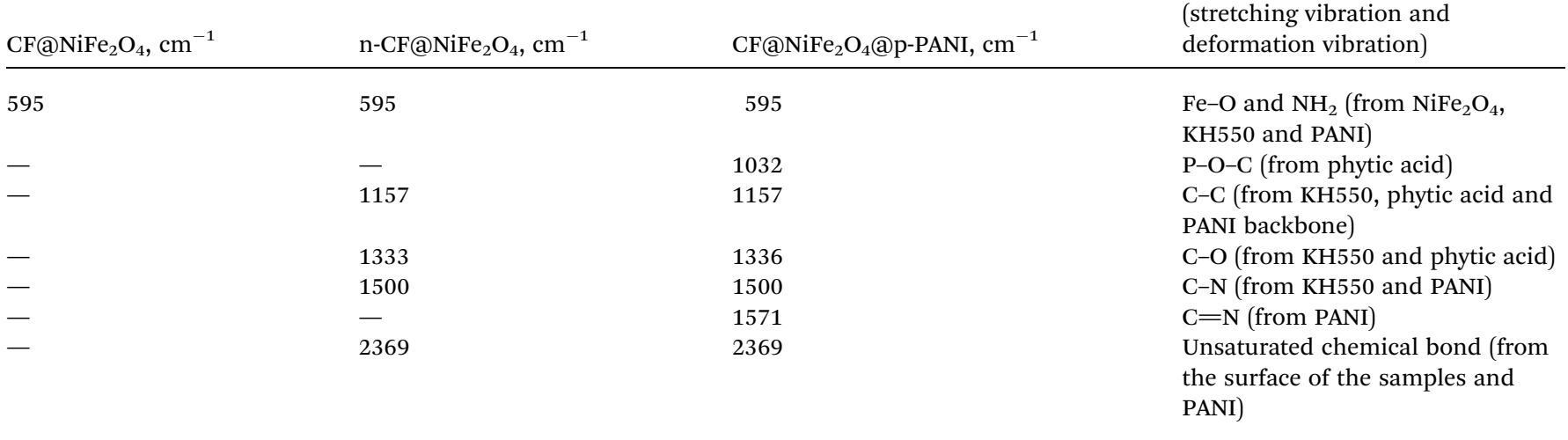

$288.3 \mathrm{eV}$ represent the $\mathrm{C}-\mathrm{C} / \mathrm{C}=\mathrm{C}, \mathrm{C}-\mathrm{N}$ and $\mathrm{C}=\mathrm{O}$ binding energies of the $\mathrm{C}$ element, respectively (Fig. 4c). In Fig. 4d, the three peaks of $-\mathrm{N}=,-\mathrm{NH}-$ and $-\mathrm{N}^{+}$- represent the three different valence states of the $\mathrm{N}$ element in the polyaniline molecular chain, which indicate that the as-synthesized polyaniline is in the doped state. In addition, the two peaks situated at $711 \mathrm{eV}$ and $724.6 \mathrm{eV}$ are assigned to the $\mathrm{F} 2 \mathrm{p}_{3 / 2}$ and $\mathrm{Fe} 2 \mathrm{p}_{1 / 2}$ binding energies, respectively (Fig. $4 \mathrm{e}$ ). The Ni2 $\mathrm{p}_{3 / 2}$ and Ni2 $\mathrm{p}_{1 / 2}$ peaks can be observed in the narrow sweep spectra in Fig. $4 \mathrm{f}$. These results further verify the chemical composition of the $\mathrm{CF} @ \mathrm{NiFe}_{2} \mathrm{O}_{4} @$ @p-PANI hybrid. ${ }^{45-47}$

The distribution of functional groups on the surface of $\mathrm{CF} @ \mathrm{NiFe}_{2} \mathrm{O}_{4}, \mathrm{n}-\mathrm{CF} @ \mathrm{NiFe}_{2} \mathrm{O}_{4}$ and the $\mathrm{CF} @ \mathrm{NiFe}_{2} \mathrm{O}_{4} @ \mathrm{p}-\mathrm{PANI}$ hybrid were investigated using FT-IR spectroscopy, and the results are shown in Fig. 5. Compared with $\mathrm{CF} @ \mathrm{NiFe}_{2} \mathrm{O}_{4}$, vibration peaks belonging to $\mathrm{C}-\mathrm{C}, \mathrm{C}-\mathrm{O}, \mathrm{C}-\mathrm{N}$ appear in the n-CF@NiFe ${ }_{2} \mathrm{O}_{4}$ sample's spectra, which illustrates the effective surface treatment of KH550. The vibration peak located at $1032 \mathrm{~cm}^{-1}$ can be assigned to the $\mathrm{P}-\mathrm{O}-\mathrm{C}$ of phytic acid, indicating the successful doping of phytic acid into the PANI molecular chain. Besides, the other corresponding adsorption peaks and assigned various modes are illustrated in Table $1 .^{48}$

Based on the magnetic loss mechanism of electromagnetic waves, the magnetic behaviors of materials have an important influence on their electromagnetic wave absorption performance; thus, the magnetic samples' hysteresis loops were measured by utilizing VSM and the results are exhibited in Fig. 6. The $\mathrm{NiFe}_{2} \mathrm{O}_{4}$, $\mathrm{CF} @ \mathrm{NiFe}_{2} \mathrm{O}_{4}$ composite and $\mathrm{CF} @ \mathrm{NiFe}_{2} \mathrm{O}_{4} @$ p-PANI hybrid all perform typical paramagnetic soft magnetic behavior, which is very beneficial for the absorption of electromagnetic waves. The magnetic saturation values of $\mathrm{NiFe}_{2} \mathrm{O}_{4}, \mathrm{CF} @ \mathrm{NiFe}_{2} \mathrm{O}_{4}$ and $\mathrm{CF} @ \mathrm{NiFe}_{2} \mathrm{O}_{4} @$ p-PANI hybrid are $56.1 \mathrm{emu} \mathrm{g}^{-1}, 41.2 \mathrm{emu} \mathrm{g}^{-1}$ and $29.9 \mathrm{emu}^{-1}$, respectively. The reduction in these samples' magnetic saturation is mainly due to the decrease in the mass ratio of the magnetic material $\mathrm{NiFe}_{2} \mathrm{O}_{4}$.

Normally, upon the incidence of microwaves onto the sample surface, the waves are reflected or transmitted; meanwhile, the contained microwave energy is absorbed by magnetic loss and dielectric loss or transforms into heat energy and scatters and disappears in the air. Considering the loss mechanism of microwaves, the absorbing mode of microwaves can mainly be divided into magnetic loss and dielectric loss, which can be calculated using the permeability $\mu^{\prime}, \mu^{\prime \prime}$ and permittivity $\varepsilon^{\prime}, \varepsilon^{\prime \prime}$, respectively. The parameter's real part $\mu^{\prime}$ and $\varepsilon^{\prime}$ represent the storage capability of the material, while the imaginary part $\mu^{\prime \prime}$ and $\varepsilon^{\prime \prime}$ stand for the dissipation capability of magnetic energy and electric energy, respectively. Based on $\mu^{\prime}, \mu^{\prime \prime}, \varepsilon^{\prime}$ and $\varepsilon^{\prime \prime}$, the corresponding reflection loss curve of the measured sample can be calculated by using eqn (1)-(4). ${ }^{49-51}$

$$
\begin{gathered}
\Gamma=\frac{Z_{\text {in }}-Z_{0}}{Z_{\text {in }}+Z_{0}} \\
Z_{0}=\left(\mu_{0} / \varepsilon_{0}\right)^{1 / 2} \\
Z_{\text {in }}=Z_{0}\left(\sqrt{\frac{\mu_{\mathrm{r}}}{\varepsilon_{\mathrm{r}}}}\right) \tanh \left[j\left(\frac{2 \pi f d}{c}\right)\left(\sqrt{\mu_{\mathrm{r}} \varepsilon_{\mathrm{r}}}\right)\right] \\
R_{\mathrm{L}}=20 \log \left(\frac{Z_{\text {in }}-Z_{0}}{Z_{\text {in }}+Z_{0}}\right)
\end{gathered}
$$

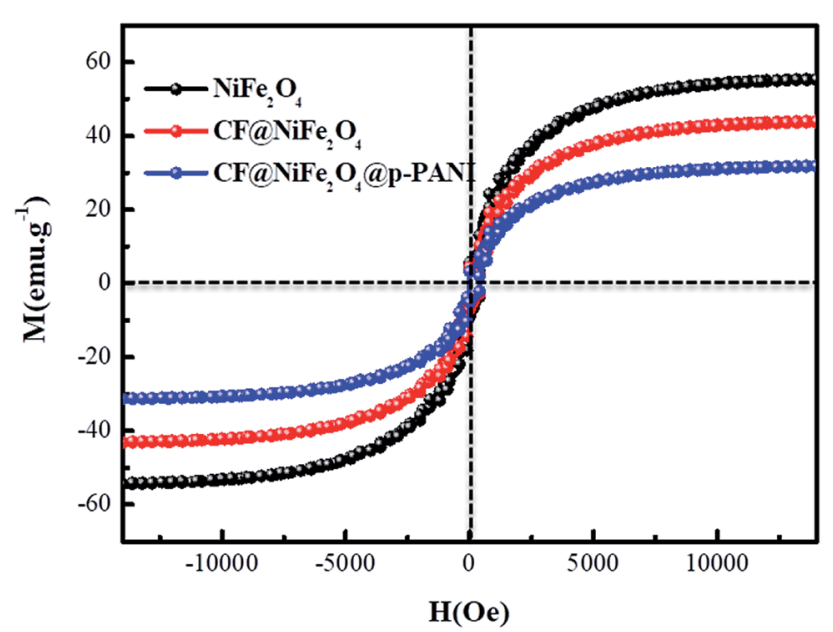

Fig. 6 Hysteresis loops of $\mathrm{NiFe}_{2} \mathrm{O}_{4}, \mathrm{CFaNiFe} \mathrm{O}_{4}$ and $\mathrm{CFCNiFe}{ }_{2}^{-}$ $\mathrm{O}_{4}$ @p-PANI hybrid. 
In these formulas, $Z_{\text {in }}$ represents the normalized input impedance of the absorbing material, $Z_{0}$ represents the impedance of free space, parameter $d$ stands for the thickness of the absorber, parameter $c$ represents the light velocity in vacuum, and the parameter $f$ signifies the frequency of the input microwave. Thus, the measured sample's thickness has a very important influence on its electromagnetic wave-absorbing capacity. The material's electromagnetic wave-absorbing performance is co-determined by its magnetic properties and dielectric properties. The electromagnetic parameters of $\mathrm{CF}, \mathrm{NiFe}_{2} \mathrm{O}_{4}$, the $\mathrm{CF} @ \mathrm{NiFe}_{2} \mathrm{O}_{4}$ composite and the $\mathrm{CF} @ \mathrm{NiFe}_{2} \mathrm{O}_{4} @$ p-PANI hybrid are exhibited in Fig. 7, and the corresponding dielectric losses $\left(\tan \delta_{\mathrm{e}}=\varepsilon^{\prime \prime} / \varepsilon^{\prime}\right)$ and magnetic losses $\left(\tan \delta_{\mathrm{m}}=\mu^{\prime \prime} / \mu^{\prime}\right)$ are also shown. Comparing the four samples' electromagnetic parameters, as a conductive material, the $\mathrm{CF}$ sample possesses the highest dielectric parameter value (including both the real and imaginary parts), while the insulating material $\mathrm{NiFe}_{2} \mathrm{O}_{4}$ possess the lowest dielectric parameter values. However, as a nonmagnetic material, the magnetic parameter values of $\mathrm{CF}$ are extremely low, which is unfavorable to the magnetic loss of electromagnetic waves. The dielectric parameter values and tan $\delta_{\mathrm{e}}$ of the $\mathrm{CF} @ \mathrm{NiFe}_{2} \mathrm{O}_{4}$ composite and $\mathrm{CF} @ \mathrm{NiFe}_{2} \mathrm{O}_{4} @ \mathrm{p}-\mathrm{PANI}$ hybrid are between those of $\mathrm{CF}$ and $\mathrm{NiFe}_{2} \mathrm{O}_{4}$; meanwhile, the magnetic parameter values are higher than those of $\mathrm{NiFe}_{2} \mathrm{O}_{4}$. The results indicate that the $\mathrm{CF} @ \mathrm{NiFe}_{2} \mathrm{O}_{4}$ composite and $\mathrm{CF} @ \mathrm{NiFe}_{2} \mathrm{O}_{4} @ \mathrm{p}$ PANI hybrid may possess a more reasonable electromagnetic matching effect. It is worth mentioning that the electromagnetic parameters of $\mathrm{NiFe}_{2} \mathrm{O}_{4}, \mathrm{CF} @ \mathrm{NiFe}_{2} \mathrm{O}_{4}$ and the $\mathrm{CF} @ \mathrm{NiFe}_{2} \mathrm{O}_{4} @ \mathrm{p}-\mathrm{PANI}$ samples all displayed resonance effects in various degrees, which can mainly be attributed to the gyromagnetic effect of $\mathrm{NiFe}_{2} \mathrm{O}_{4}$.
According to the measured $\varepsilon^{\prime}, \varepsilon^{\prime \prime}, \mu^{\prime}, \mu^{\prime \prime}$ parameters, the reflection loss patterns ranging from 2-18 GHz of CF, $\mathrm{NiFe}_{2} \mathrm{O}_{4}, \mathrm{CF} @ \mathrm{NiFe}_{2} \mathrm{O}_{4}$ composite and $\mathrm{CF} @ \mathrm{NiFe}_{2} \mathrm{O}_{4} @$ @p-PANI hybrid samples were calculated, and the results are exhibited in Fig. 8. As can be observed in the figure, as a nonmagnetic material, the EM wave-absorbing capacity of the pure carbon fiber is poor, and its minimum reflection loss $\left(R_{\mathrm{Lmin}}\right)$ value is $-\mathbf{1 5 . 6} \mathrm{dB}$ with a specimen thickness of 1.6 $\mathrm{mm}$. Conversely, due to the extremely poor conductivity, the $\mathrm{NiFe}_{2} \mathrm{O}_{4}$ sample's EM wave performance is also inferior, with a minimum reflection loss value of $-12 \mathrm{~dB}$. However, the $\mathrm{CF} @ \mathrm{NiFe}_{2} \mathrm{O}_{4}$ composite possesses a strong EM wave-absorption capacity, which can reach up to $-37 \mathrm{~dB}$. When further combined with phytic acid-doped PANI, the EM wave-absorbing performance of the CF@NiFe $\mathrm{O}_{4} @$ @p-PANI hybrid is enhanced, achieving $-46 \mathrm{~dB}$, which can mainly be attributed to its fair electromagnetic matching.

To further investigate the EM wave absorption performance of $\mathrm{CF}, \mathrm{NiFe}_{2} \mathrm{O}_{4}, \mathrm{CF} @ \mathrm{NiFe}_{2} \mathrm{O}_{4}$ and $\mathrm{CF} @ \mathrm{NiFe}_{2} \mathrm{O}_{4} @$ @PANI hybrid, their $\left|Z_{\text {in }} / Z_{0}\right|$ values were calculated to estimate their impedance matching, which are shown in Fig. 9a. A value of $\left|Z_{\text {in }} / Z_{0}\right|$ that is closer to one indicates that the material possesses better impedance matching characteristics. Compared with the $\mathrm{CF}$ and $\mathrm{NiFe}_{2} \mathrm{O}_{4}$ samples, the $\mathrm{CF} @ \mathrm{NiFe}_{2} \mathrm{O}_{4}$ and $\mathrm{CF} @ \mathrm{NiFe}_{2} \mathrm{O}_{4} @$ @-PANI hybrid samples' $\left|Z_{\text {in }} / Z_{0}\right|$ values are closer to one, which illustrates that superior impedance matching can be obtained with $\mathrm{CF} @ \mathrm{NiFe}_{2} \mathrm{O}_{4}$ and $\mathrm{CF} @ \mathrm{NiFe}_{2} \mathrm{O}_{4}$ @p-PANI hybrid. The attenuation constant $\alpha$ can be expressed as eqn (5), which quantitatively represents the attenuation effect in the frequency range. The corresponding $\alpha$ values of the four samples are exhibited in Fig. 9b. Compared with $\mathrm{NiFe}_{2} \mathrm{O}_{4}$ (a)

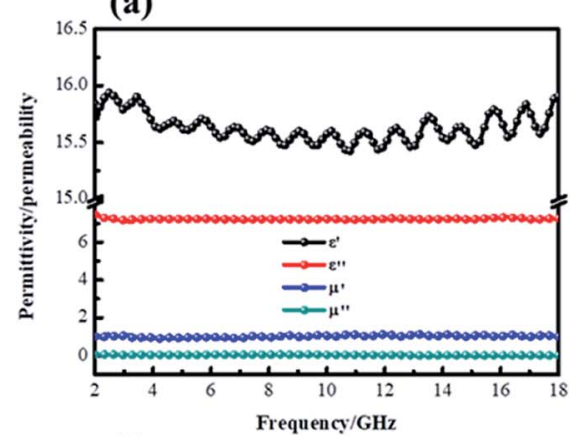

(d)

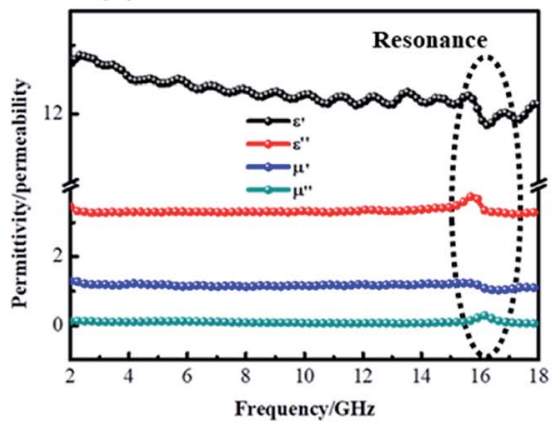

(b)

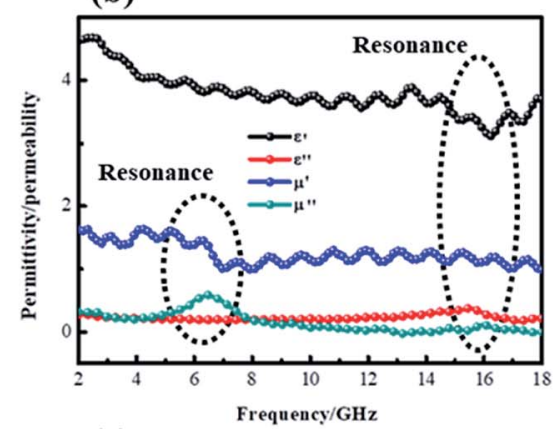

(e)

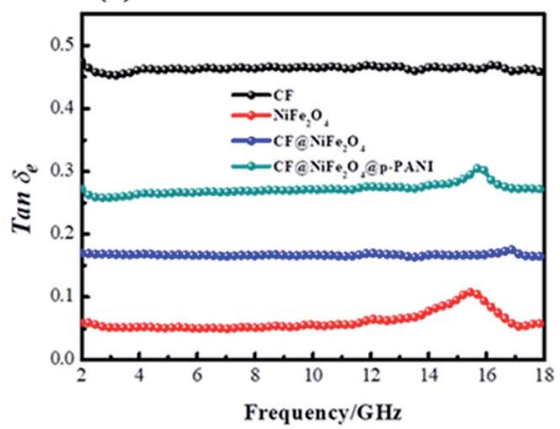

(c)

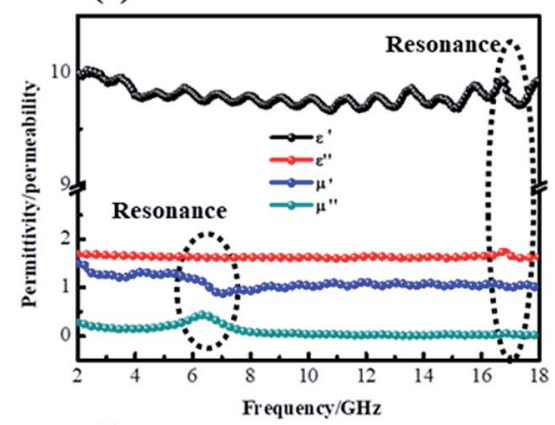

(f)

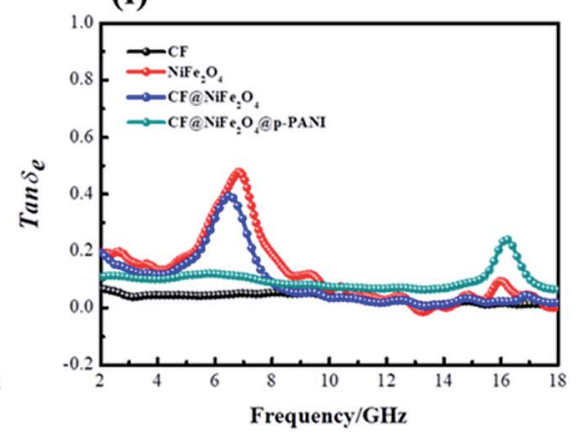

Fig. 7 Electromagnetic parameters of $\mathrm{CF}(\mathrm{a}), \mathrm{NiFe}_{2} \mathrm{O}_{4}$ (b), CFaNiFe $\mathrm{O}_{4}$ (c) and CFaNiFe $\mathrm{O}_{4}$ (ap-PANI hybrid (d), dielectric loss (e) and magnetic loss (f). 
(a)

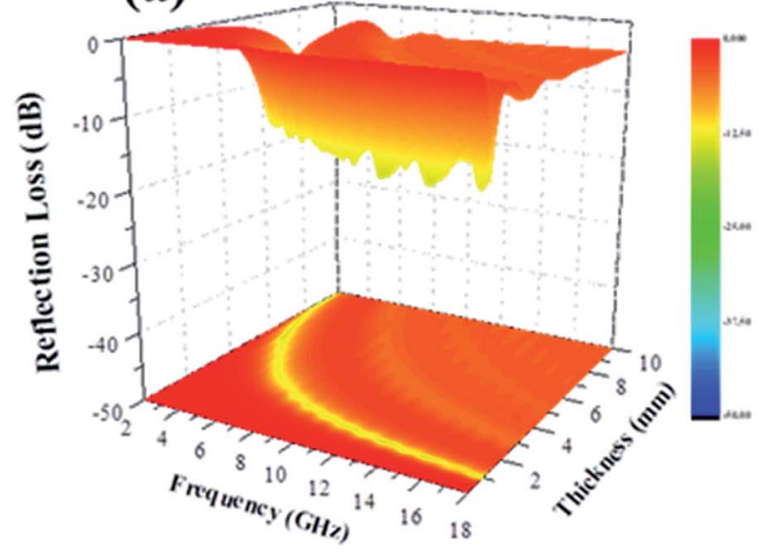

(c)

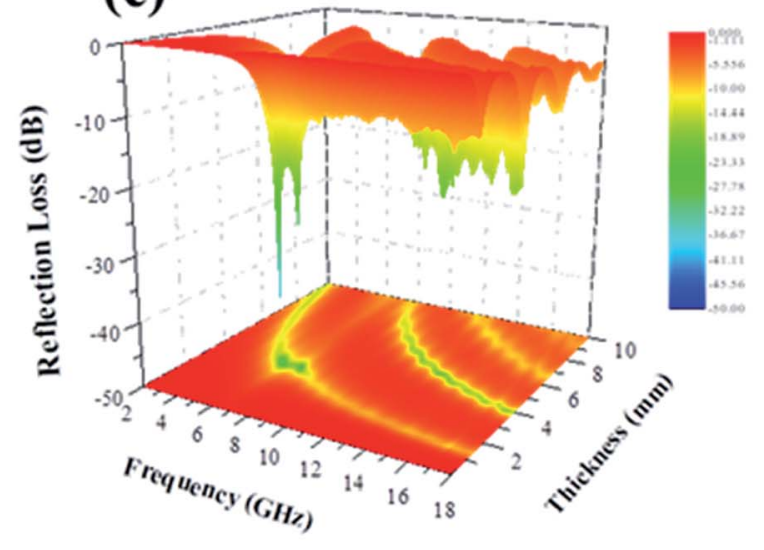

(b)

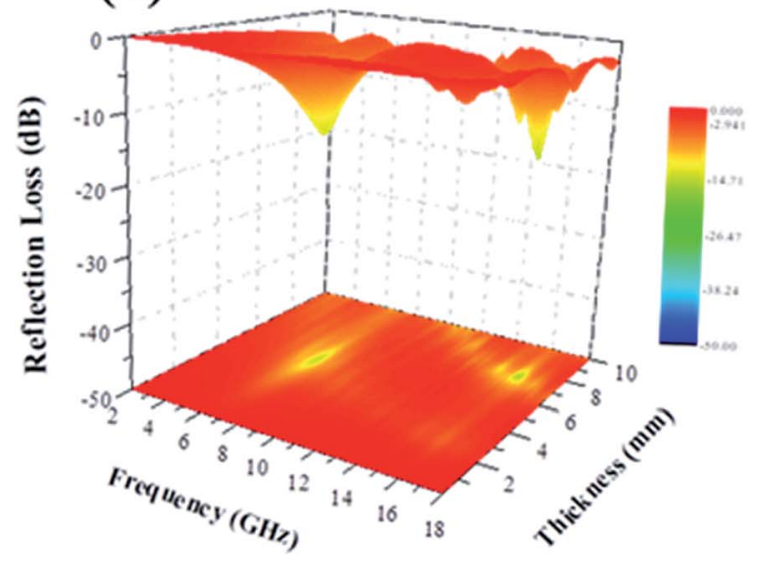

(d)

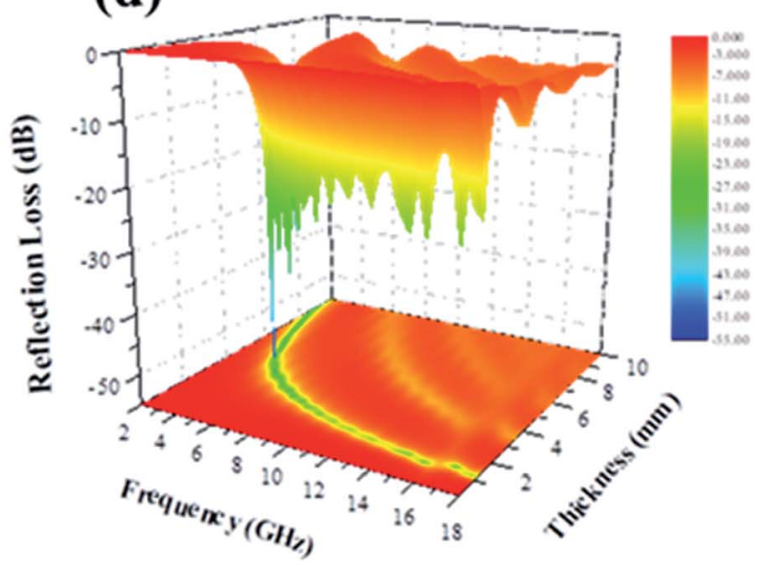

Fig. 8 Reflection loss patterns of $\mathrm{CF}(\mathrm{a}), \mathrm{NiFe}_{2} \mathrm{O}_{4}$ (b), CF@NiFe $\mathrm{O}_{4}$ (c) and CF@NiFe $\mathrm{O}_{4}$ (ap-PANI hybrid (d).

and $\mathrm{CF} @ \mathrm{NiFe}_{2} \mathrm{O}_{4}$, the hybrid shows a higher attenuation constant $\alpha$, which is beneficial for enhancing its EM wave absorption capability..$^{52-54}$

$$
\alpha=\frac{\sqrt{2} \pi f}{c} \sqrt{\left(\mu^{\prime \prime} \varepsilon^{\prime \prime}-\mu^{\prime} \varepsilon^{\prime}\right)+\sqrt{\left(\mu^{\prime \prime} \varepsilon^{\prime \prime}-\mu^{\prime} \varepsilon^{\prime}\right)^{2}+\left(\mu^{\prime} \varepsilon^{\prime \prime}-\mu^{\prime \prime} \varepsilon^{\prime}\right)^{2}}}
$$

The EM wave-absorbing performance of the as-synthesized $\mathrm{CF} @ \mathrm{NiFe}_{2} \mathrm{O}_{4} @ p-P A N I$ hybrid was investigated in detail, and the relative results are shown in Fig. 10. In Fig. 10a and b, the hybrid's $R_{\mathrm{Lmin}}$ can reach up to $-46 \mathrm{~dB}$ with a sample thickness of $2.9 \mathrm{~mm}$, which is smaller than any other thickness, indicating that the hybrid possesses the highest absorption efficiency at this thickness. Fig. 10c exhibits the effective (a)

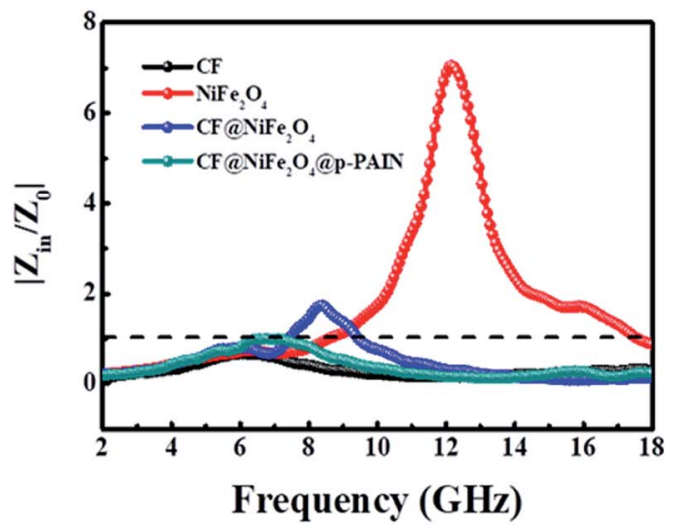

(b)

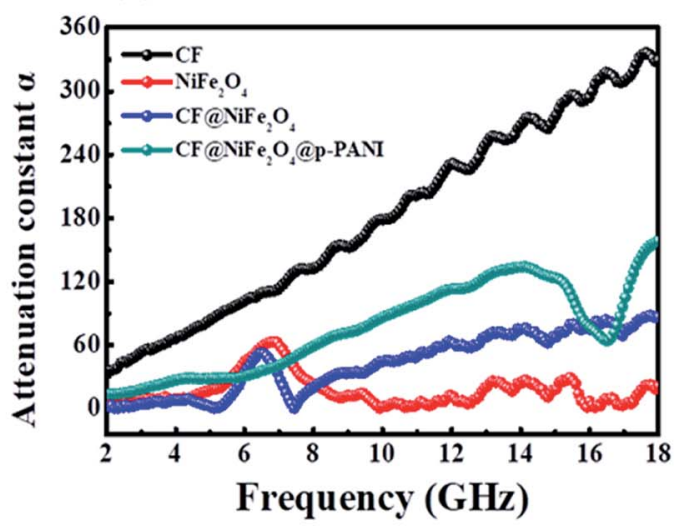

Fig. 9 The impedance matching values of samples at different frequencies (a) and their attenuation constant $\alpha$ (b). 
(a)

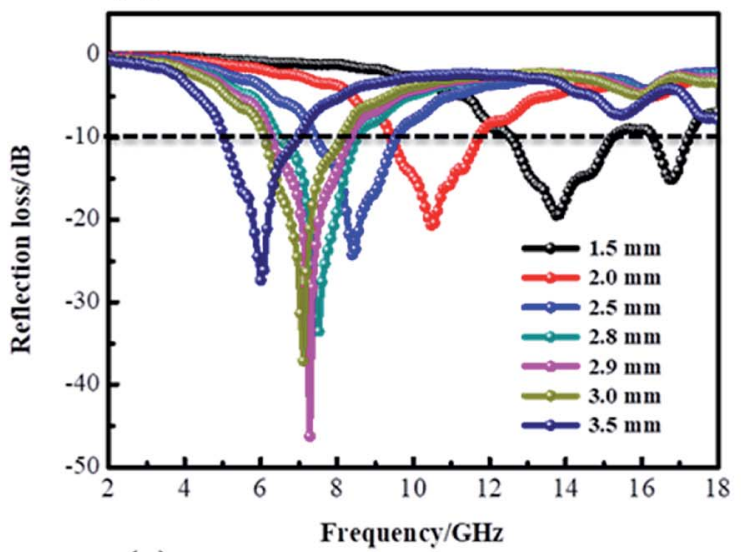

(c)

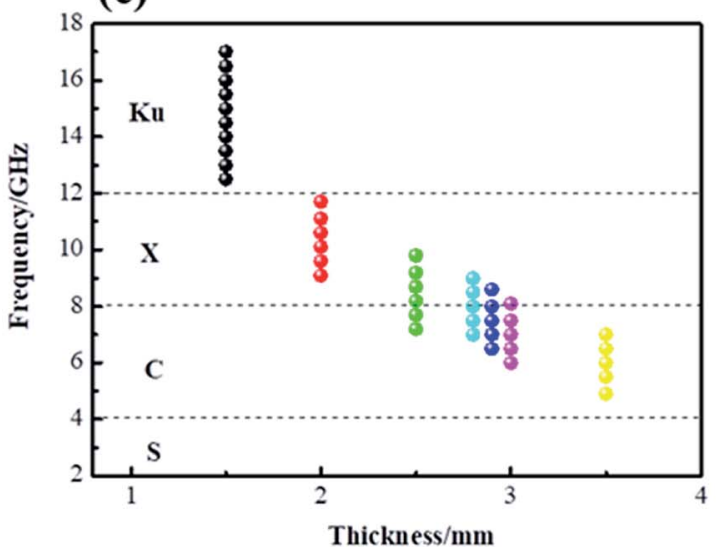

(b)

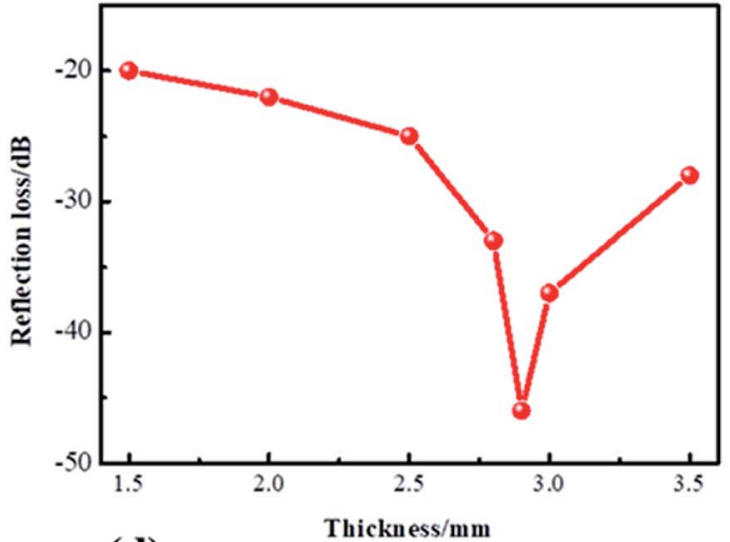

(d)

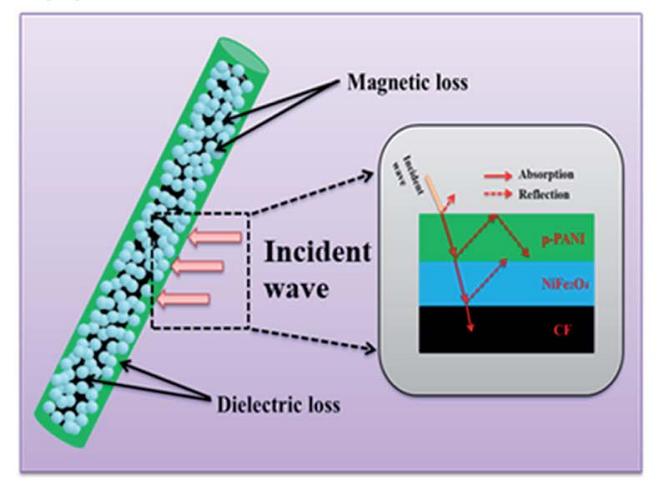

Fig. $10 R_{\mathrm{L}}$ patterns (a), $R_{\mathrm{Lmin}}$ values (b), EAB at different thicknesses (c) and sketch illustration of the mechanism of the EM wave absorption (d) for the CF@NiFe $\mathrm{O}_{4} @$ ap-PANI hybrid.

absorption bandwidth (EAB, $R_{\mathrm{L}}<-10 \mathrm{~dB}$ ) at $1.5 \mathrm{~mm}, 2.0 \mathrm{~mm}$, $2.5 \mathrm{~mm}, 2.8 \mathrm{~mm}, 2.9 \mathrm{~mm}, 3.0 \mathrm{~mm}$ and $3.5 \mathrm{~mm}$ when the thickness is $1.5 \mathrm{~mm}$; the hybrid's EAB width extends up to 5 $\mathrm{GHz}$, from $12.5 \mathrm{GHz}$ to $17.5 \mathrm{GHz}$, almost covering all of the $\mathrm{Ku}$ band. These results indicate that the $\mathrm{CF} @ \mathrm{NiFe}_{2} \mathrm{O}_{4} @ \mathrm{p}-\mathrm{PANI}$ hybrid has excellent electromagnetic wave-absorbing performance, both in terms of its absorbing efficiency and EAB width. A sketch illustration of the mechanism of the electromagnetic wave absorption by the $\mathrm{CF} @ \mathrm{NiFe}_{2} \mathrm{O}_{4} @$ @-PANI hybrid is displayed in Fig. 10d. First, the conductive material CF, PANI and the magnetic material $\mathrm{NiFe}_{2} \mathrm{O}_{4}$ achieve reasonable electromagnetic matching in the hybrid. Materials with good electrical conductivity may produce skin effects and additional reflection at the interface between the material and air; this offers effective electromagnetic attenuation. Secondly, the multiple interfaces that emerged due to its layer-by-layer cladding structure can increase the absorption times of EM waves. Thirdly, PANI is an effective coating that prevents $\mathrm{NiFe}_{2} \mathrm{O}_{4}$ from further oxidation, thus enhancing the stability of $\mathrm{NiFe}_{2} \mathrm{O}_{4}$ in the heterostructures. Moreover, the introduction of lightweight PANI may improve

Table 2 The electromagnetic wave absorbing performance of analogous absorbers

\begin{tabular}{|c|c|c|c|c|c|c|c|}
\hline Sample & Frequency range $(\mathrm{GHz})$ & Weight percent of filler & Adhesive & Thickness & $R_{\mathrm{Lmin}}$ & EAB width (GHz) & Ref. \\
\hline PANI@p-C@NiFe ${ }_{2} \mathrm{O}_{4}$ & $2-18$ & $30 \%$ & Paraffin wax & $2.5 \mathrm{~mm}$ & $-37 \mathrm{~dB}$ & 3.9 & 30 \\
\hline NanoG/NiFe ${ }_{2} \mathrm{O}_{4} /$ PANI & $8.2-12.4$ & $30 \%$ & Paraffin wax & $2.5 \mathrm{~mm}$ & $-30 \mathrm{~dB}$ & 2.8 & 32 \\
\hline $\mathrm{PANI} / \mathrm{MnO}_{2} / \mathrm{CF}$ & $8.2-12.4$ & $30 \%$ & Paraffin wax & $2.5 \mathrm{~mm}$ & $-22 \mathrm{~dB}$ & 3.0 & 60 \\
\hline $\mathrm{NiFe}_{2} \mathrm{O}_{4} @ \mathrm{MnO}_{2}$ & $2-18$ & $30 \%$ & Paraffin wax & $2.0 \mathrm{~mm}$ & $-25 \mathrm{~dB}$ & 2.7 & 31 \\
\hline $\mathrm{PANI} / \mathrm{NiFe}_{2} \mathrm{O}_{4}$ & $1-6$ & $66 \%$ & Epoxy & N.A & $-20.3 \mathrm{~dB}$ & 2.8 & 61 \\
\hline PANI@Ni@CF & $8.2-12.4$ & $20 \%$ & Paraffin wax & $2.0 \mathrm{~mm}$ & $-12.4 \mathrm{~dB}$ & 1.2 & 62 \\
\hline 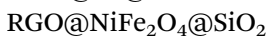 & $2-18$ & $30 \%$ & Paraffin wax & $3.0 \mathrm{~mm}$ & $-42 \mathrm{~dB}$ & 11.5 & 63 \\
\hline $\mathrm{CF} @ \mathrm{NiFe}_{2} \mathrm{O}_{4} @ P A N I$ & $2-18$ & $30 \%$ & Paraffin wax & $2.9 \mathrm{~mm}$ & $-46 \mathrm{~dB}$ & 2.0 & This work \\
\hline
\end{tabular}


the interface between the carbon fibers and matrix, which may result in lightweight composites with better matrix-filler compatibility. Besides, the complexation between phytic acid and $\mathrm{NiFe}_{2} \mathrm{O}_{4}$ and the adsorption effect of KH550 can further enhance the interfacial interaction, which can further enhance the hybrid's EM wave performance by its eddy current loss, interfacial polarizations and interface relaxation. When compared with other reported analogous EM wave absorbers, including PANI@p-C@ $\mathrm{NiFe}_{2} \mathrm{O}_{4}, \mathrm{NanoG} / \mathrm{NiFe}_{2} \mathrm{O}_{4} / \mathrm{PANI}, \mathrm{PANI} /$ $\mathrm{MnO}_{2} / \mathrm{CF}, \mathrm{NiFe}_{2} \mathrm{O}_{4} @ \mathrm{MnO}_{2}, \mathrm{PANI} / \mathrm{NiFe}_{2} \mathrm{O}_{4}, \mathrm{PANI} @ \mathrm{Ni} @ \mathrm{CF}$ and RGO@NiFe ${ }_{2} \mathrm{O}_{4} @ \mathrm{SiO}_{2}$ (Table 2), the as-synthesized CF@NiFe ${ }_{2}-$ $\mathrm{O}_{4} @$ @-PANI hybrid shows excellent EM wave absorption properties. ${ }^{55-59}$

\section{Conclusion}

In summary, a uniform $\mathrm{CF} @ \mathrm{NiFe}_{2} \mathrm{O}_{4} @$ @-PANI hybrid was facilely fabricated via a two-step method involving a solvothermal reaction and in situ polymerization. The morphological structure, chemical composition, magnetic behavior, surface functional group distribution and EM wave-absorbing properties of the as-prepared hybrid were systematically evaluated. The results indicate that the hybrid possesses excellent EM wave-absorbing performance, and its reflection loss value can reach up to $-46 \mathrm{~dB}$ with a specimen thickness of $2.9 \mathrm{~mm}$. The superior EM performance of the hybrid can be attributed to its fair electromagnetic matching, multiple interfaces and eddy current loss.

\section{Conflicts of interest}

There are no conflicts to declare.

\section{Acknowledgements}

This work was financially supported by the National Natural Science Foundation of China (No. 51407134, No. 51801001), China Postdoctoral Science Foundation (No. 2016M590619, No. 2016M601878), Natural Science Foundation of Shandong Province (No. ZR2019YQ24), Qingdao Postdoctoral Application Research Project, Key Laboratory of Engineering Dielectrics and Its Application (Harbin University of Science and Technology), Ministry of Education (No. KFZ1803), Provincial Key Research and Development Program of Shaanxi (No. 2019GY-197), Key Project of Baoji University of Arts and Sciences (No. ZK2018051), Baoji Science and Technology Project (No. 16RKX1-29) and Baoji Engineering Technology Research Center for Ultrafast Optics and New Materials (No. 2015CXNL-1-3). Feng AL is supported by the Thousand Talents Plan for Young Professionals of Shaanxi Province.

\section{References}

1 S. Ji, C. Li, Z. Zhang, X. Jiang and L. Yu, Synth. Met., 2018, 239, 59-65.

2 Z. Jia, Z. Gao, A. Feng, Y. Zhang, C. Zhang, G. Nie, K. Wang and G. Wu, Composites, Part B, 2019, 176, 107246.
3 M. Chen, W. Zhao, M. Zhu, X. Li, C. Xu, H. Chen and J. Xu, Chem. Sci., 2019, 10, 4141-4147.

4 Z. Gao, Z. Jia, J. Zhang, A. Feng, Z. Huang and G. Wu, J. Mater. Sci.: Mater. Electron., 2019, 30, 13474-13487.

5 J. Liu, H. Liang, Y. Zhang, G. Wu and H. Wu, Composites, Part B, 2019, 176, 107240.

6 I. Abdalla, A. Salim, M. Zhu, J. Yu, Z. Li and B. Ding, ACS Appl. Mater. Interfaces, 2018, 10, 44561-44569.

7 X. L. Chen, Z. R. Jia, A. L. Feng, B. B. Wang, X. H. Tong, C. H. Zhang and G. L. Wu, J. Colloid Interface Sci., 2019, 553, 465-474.

8 J. Fang, T. Liu, Z. Chen, Y. Wang, W. Wei, X. Yue and Z. Jiang, Nanoscale, 2016, 8, 8899-8909.

9 C. Huang, Y. Ding, C. Hao, S. Zhou, X. Wang, H. Gao, L. Zhu and J. Wu, Chem. Eng. J., 2019, 378, 122202.

10 J. Fang, Z. Chen, W. Wei, Y. Li, T. Liu, Z. Liu and X. Yue, RSC $A d v .$, 2016, 6, 4695-4704.

11 I. Abdalla, J. Yu, Z. Li and B. Ding, Composites, Part B, 2018, 155, 397-404.

12 Y. Wang, X. Gao, C. Lin, L. Shi, X. Li and G. Wu, J. Alloys Compd., 2019, 785, 765-773.

13 J. Fang, Z. Chen, W. Wei, Y. Li, T. Liu, Z. Liu and X. Yue, RSC Adv., 2015, 5, 50024-50032.

14 I. Abdalla, J. Shen, J. Yu, Z. Li and B. Ding, Sci. Rep., 2018, 8, 12402.

15 F. M. Alanagha, A. B. Khiabanib and A. A. Asl, Compos. Sci. Technol., 2017, 150, 65-78.

16 G. Wu, Z. Jia, Y. Cheng, H. Zhang, X. Zhou and H. Wu, Appl. Surf. Sci., 2019, 10, 472-478.

17 C. Huang, C. Hao, Z. Ye, S. Zhou, X. Wang, L. Zhu and J. Wu, Nanoscale, 2019, 11, 10114-10128.

18 A. Feng, G. Wu, C. Pan and Y. Wang, J. Nanosci. Nanotechnol, 2017, 17, 3786-3791.

19 J. Ma, W. Liu, B. Quan, X. Liang and G. Ji, J. Colloid Interface Sci., 2017, 504, 479-484.

20 X. Xue, H. Yan and Y. Fu, Solid State Ionics, 2019, 335, 1-6.

21 A. Feng, G. Wu, C. Pan and Y. Wang, J. Nanosci. Nanotechnol., 2017, 17, 3859-3863.

$22 \mathrm{~W} . \mathrm{Wu}, \mathrm{C} . \mathrm{Yu}, \mathrm{J}$. Chen and Q. Yang, Int. J. Environ. Anal. Chem., 2019, DOI: 10.1080/03067319.2019.1636977.

23 X. Yang, Y. Guo, Y. Han, Y. Li, T. Ma, M. Chen, J. Kong, J. Zhu and J. Gu, Composites, Part B, 2019, 175, 107070.

24 M. Sabet, H. Jahangiri and E. Ghashghaei, Synth. Met., 2017, 224, 18-26.

25 X. Chen, T. Shi, K. Zhong, G. Wu and Y. Lu, Chem. Eng. J., 2020, 379, 122240.

26 H. L. Xu, X. W. Yin, M. Zhu, M. H. Li, H. Zhang, H. J. Wei, L. T. Zhang and L. F. Cheng, Carbon, 2019, 142, 346-353.

27 X. Zhou, Z. Jia, X. Wang, J. Liu, M. Zhang, H. Cao and G. Wu, Carbon, 2019, 152, 827-836.

28 Z. Jia, B. Wang, A. Feng, J. Liu, M. Zhang, Z. Huang and G. Wu, J. Alloys Compd., 2019, 799, 216-223.

29 Y. Sun, J. W. Zhang, Y. Zong, X. Deng, H. Y. Zhao, J. Feng, M. He, X. H. Li, Y. Peng and X. L. Zheng, ACS Appl. Mater. Interfaces, 2019, 11, 6374-6383.

30 X. Chen, K. Zhong, T. Shi, X. Meng, G. Wu and Y. Lu, Synth. Met., 2019, 248, 59-67. 
31 Y. Wang, Y. Fu, X. Wu, W. Zhang, Q. Wang and J. Li, Ceram. Int., 2017, 43, 11367-11375.

32 X. L. Chen and S. H. Qi, J. Sol-Gel Sci. Technol., 2017, 81, 824.

33 R. S. Yadav, I. Kuřitka, J. Vilcakova and D. Skoda, Composites, Part B, 2019, 166, 95-111.

34 H. Yan, Y. Fu, X. Wu, X. Xue, C. Li and L. Zhang, Solid State Ionics, 2019, 336, 95-101.

35 J. Feng, Y. Zong, Y. Sun, Y. Zhang, X. Wang, G. Long, Y. Wang, X. Li and X. Zheng, Chem. Eng. J., 2018, 345, 441451.

36 Y. Cheng, J. M. Cao, Y. Li, Z. Y. Li, H. Q. Zhao, G. B. Ji and Y. W. Du, ACS Sustainable Chem. Eng., 2018, 6, 1427-1435.

37 K. Nasouri and A. M. Shoushtari, Compos. Sci. Technol., 2017, 145, 46-54.

38 X. Chen and S. Qi, J. Mater. Sci.: Mater. Electron., 2016, 27, 13099-13104.

39 J. T. Kim, C. W. Park and B. J. Kim, Synth. Met., 2017, 223, 212-217.

40 Z. Jia, B. Wang, A. Feng, J. Liu, C. Zhang, M. Zhang and G. Wu, Ceram. Int., 2019, 13, 15854-15859.

41 J. Liu, R. Che, H. Chen, F. Zhang, F. Xia, Q. Wu and M. Wang, Small, 2012, 8, 1214-1221.

42 D. Lan, M. Qin, R. Yang, H. Wu, Z. Jia, K. Kou, G. Wu, Y. Fan, Q. Fu and F. Zhang, J. Mater. Sci.: Mater. Electron., 2019, 30, 8771-8776.

43 J. Wu, Z. Ye, H. Ge, J. Chen, W. Liu and Z. Liu, J. Colloid Interface Sci., 2017, 506, 217-226.

44 H. L. Lv, Z. H. Yang, S. J. H. Ong, C. Wei, H. B. Liao, S. B. Xi, Y. H. Du, G. B. Ji and Z. C. J. Xu, Adv. Funct. Mater., 2019, 14, 1900163.

45 Y. Wang, W. Z. Zhang, X. M. Wu, C. Y. Luo, Q. G. Wang, J. H. Li and L. Hu, Synth. Met., 2017, 228, 18-24.

46 H. Zhang, B. Wang, A. Feng, N. Zhang, Z. Jia, Z. Huang, X. Liu and G. Wu, Composites, Part B, 2019, 167, 690-699.

47 H. L. Lv, Z. H. Yang, P. L. Wang, G. B. Ji, J. Z. Song, L. R. Zheng, H. B. Zeng and Z. J. Xu, Adv. Mater., 2018, 30, 1706343.
48 Z. Wang, M. Yang, Y. Cheng, J. Liu, B. Xiao, S. Chen, J. Huang, Q. Xie, G. Wu and H. Wu, Composites, Part A, 2019, 118, 302-311.

49 G. Wu, Y. Cheng, Z. Yang, Z. Jia, H. Wu, L. Yang, H. Li, P. Guo and H. Lv, Chem. Eng. J., 2018, 333, 519-528.

50 T. Hou, B. Wang, Z. Jia, H. Wu, D. Lan, Z. Huang, A. Feng, M. Ma and G. Wu, J. Mater. Sci.: Mater. Electron., 2019, 30, 10961-10984.

51 A. Feng, Z. Jia, Y. Zhao and H. Lv, J. Alloys Compd., 2018, 745, 547-554.

52 S. Gupta, C. Chang, C. H. Lai and N. H. Tai, Composites, Part $B, 2019,164,447-457$.

53 J. Li, J. Ma, S. Chen, Y. Huang and J. He, Mater. Sci. Eng., C, 2018, 89, 25-32.

54 H. Zhao, L. Hou, S. Bi and Y. Lu, ACS Appl. Mater. Interfaces, 2017, 9, 33059-33070.

55 G. Wu, H. Zhang, X. Luo, L. Yang and H. Lv, J. Colloid Interface Sci., 2019, 536, 548-555.

56 Y. Wang, X. Gao, L. Zhang, X. Wu, Q. Wang, C. Luo and G. Wu, Appl. Surf. Sci., 2019, 480, 830-838.

57 W. Wu, C. Yu, Q. Wang, F. Zhao, H. He, C. Liu and Q. Yang, Crit. Rev. Food Sci., 2019, DOI: 10.1080/03067319.2019.1636977.

58 S. Y. Chen, Y. H. Cheng, Q. Xie, B. Xiao, Z. D. Wang, J. Y. Liu and G. L. Wu, Composites, Part A, 2019, 120, 84-94.

59 M. Cao, J. Yang, W. Song, D. Zhang, B. Wen, H. Jin, Z. Hou and J. Yuan, ACS Appl. Mater. Interfaces, 2012, 4, 6949-6956.

60 J. Wang, B. Cheng, H. Qiu and S. Qi, J. Electron. Mater., 2018, 47, 5564-5571.

61 Y. C. Du, W. W. Liu, R. Qiang, Y. Wang, X. J. Han, J. Ma and P. Xu, ACS Appl. Mater. Interfaces, 2014, 6, 12997-13006.

62 X. L. Chen, X. W. Wang, L. D. Li and S. H. Qi, J. Mater. Sci.: Mater. Electron., 2016, 27, 5607-5612.

63 Y. Wang, W. Zhang, C. Luo, X. Wu, Q. Wang and W. Chen, Ceram. Int., 2016, 42, 17374-17381. 